1 Translational biology of nematode effectors. Or, to put it another way, functional analysis of

2 effectors - what's the point?

3

4

5 Sophie Mantelin ${ }^{1}$, Peter Thorpe ${ }^{1}$ and John T. Jones ${ }^{1,2^{*}}$

6

7

$8{ }^{1}$ Dundee Effector Consortium, Cell and Molecular Sciences, The James Hutton Institute, Invergowrie,

9 Dundee, DD2 5DA, UK

$10{ }^{2}$ Biology Department, University of St Andrews, St Andrews, Fife, KY16 9TZ, UK 11

12 *Corresponding Author: john.jones@hutton.ac.uk jj33@st-andrews.ac.uk 13

14 
15 Summary: There has been a huge amount of work put into identifying and characterising effectors from plant-parasitic nematodes in recent years. Although this work has provided insights into the mechanisms by which nematodes can infect plants, the potential translational outputs of much of this research are not always clear. This short article will summarise how developments in effector biology have allowed, or will allow, new control strategies to be developed, drawing on examples from nematology and from other pathosystems.

21

22

Keywords: effector, plant-parasitic nematode, translational biology 
Biotrophic parasitism of plants is a strategy used by a wide taxonomic range of organisms, including nematodes, insects, fungi, oomycetes and bacteria, and there are considerable parallels between many aspects of the life cycles of these organisms. Each needs to overcome the physical and chemical barriers that plants use to protect themselves and many will need to overcome or suppress induced plant defence responses. All will need to extract the nutrients required for development from their chosen hosts and many, in doing so, will induce cellular or physiological modifications that improve the nutritional qualities of the host. For example, cyst nematodes exploit plant sugars as a food source (Danchin et al., 2016) and sucrose transporters are upregulated during the early stages of the interaction between cyst nematodes and their hosts, allowing food to be transported into the developing syncytium (Hoffman et al., 2007). Similarly, several SWEET genes encoding putative sugar transporters are induced in rice in response to the pathogenic bacteria Xanthomonas oryzae pv. oryzae, that can support bacterial development (Streubel et al., 2013). A more direct example of a pathogen modifying the host comes from the fungal pathogen Ustilago mays, which introduces a chorismate mutase into the cells of its host during infection that adjusts the metabolic status of the host through metabolic priming (Djamei et al., 2011).

At a molecular level, the interactions of plant pathogens with their hosts are mediated largely by effectors. There are many different definitions of "effectors" used in different branches of plant pathology. For the purposes of this article we use the relatively broad definition suggested by Bird et al., (2014): "Any pathogen molecule that suppresses host defences or manipulates the host to allow provision of food to the pathogen". Effectors are secreted from the pathogen into their hosts and in plant-parasitic nematodes they arise mainly from the subventral and dorsal pharyngeal gland cells, from where they are secreted into the host through the stylet. Effectors may also originate from other tissues and it has recently been shown that some effectors are secreted from the amphids into the apoplast surrounding the feeding nematode (Eves van den Akker et al., 2014a). Changes in the morphology of the pharyngeal gland cells during development of cyst and root-knot nematodes suggest that the products of the subventral gland cells (which are large and active in the invasive second stage juvenile) are likely to be important at the early stages of the host-parasite interaction while those of the dorsal gland cell (which grows and becomes more active during the parasitic stages) are likely to be more important during the parasitic process (Hussey \& Mimms, 1990).

Effectors play a central role in the biology of plant-parasitic nematodes and consequently a great deal of effort has been put into identifying the genes encoding these proteins. Several detailed reviews on this topic have been published recently (e.g. Goverse \& Smant, 2014; Mitchum et al., 2013; Haegeman et al., 2012); here we provide only the briefest of outlines and recommend these 
reviews for further details. The most productive strategy for identification of effectors has been analysis of transcriptome (or Expressed Sequence Tag - EST) sequences, either from whole nematodes or from aspirated gland cell contents (Noon et al., 2015; Maier et al., 2013; Gao et al., 2003; Huang et al., 2003). This analysis has been used for identification of effectors from sedentary endoparasites including cyst and root-knot nematodes (e.g. Jones et al., 2009; Petitot et al., 2016), Nacobbus aberrans (Eves van den Akker et al., 2014b) and Rotylenchulus reniformis (Wubben et al., 2010), as well as for a variety of migratory endoparasites (Kikuchi et al., 2007; Haegeman et al., 2009; Haegeman et al., 2011). More recently, genome sequences of plant parasitic nematodes have become available and are now being analysed for the presence of effectors (Danchin et al., 2013; Thorpe et al., 2014, Eves van den Akker et al., 2016). In all cases, effectors are first identified by a combination of bioinformatic analyses. These candidate genes are validated by functional assays such as (i) confirmation that the genes are expressed in secretory organs (most often the gland cells) from which they can be delivered into the host and (ii) evaluation of their contribution to fitness of the pathogen by silencing in the nematode. High-throughput and relatively low cost sequencing approaches mean that these types of approaches are now being applied to a far wider range of nematodes than was previously feasible; this is clearly illustrated by the development of the 959 nematode genomes initiative project (Kumar et al., 2012; http://www.nematodes.org/nematodegenomes). Furthermore, new tools are being developed that allow more focused sequencing targeted specifically at effectors that will make effector identification even more accessible. For example, a method for isolation of gland cells and sequencing of amplified RNA has been described that has been used for identification of effectors in three plant-parasitic nematodes (Maier et al., 2013). In addition, capture array protocols have been described that allow specific subclasses of genes to be enriched from a genome prior to sequencing, allowing sequence depth to be focused on genes of interest while ignoring other parts of the genome. This approach has allowed, for example, sequencing of the full resistance gene complement of potato, tomato and wheat (Jupe et al., 2013; Andolfo et al., 2014; Steuernagel et al., 2016) and is currently being applied to capture and sequencing of effectors. This approach is likely to be of particular value for comparative analysis of relatively closely related populations of a nematode species for which the effector complement is known, as design of the probes for the capture array requires prior knowledge of the sequence types that are being sought.

The outputs of these projects have led to the identification of a wide range of effectors from a variety of economically important plant-parasitic nematode species. This has enabled elegant functional studies that have demonstrated the importance of effectors in several aspects of the biology of plant-parasitic nematodes. For example, effectors have been identified that suppress host 
defence responses (Jaouannet et al., 2012; Postma et al., 2012; Lozano-Torres et al., 2014; Niu et al., 2016) while others have been shown to interact with auxin transporter proteins (Lee et al., 2011) or exhibit transcriptional activation activity in their host (Zhang et al., 2015) and these may therefore have an important role in development of the feeding site.

It is clear that functional studies of effectors provide valuable information about the molecular mechanisms by which nematodes infect plants. However, the practical outputs that are emerging from effector biology are not always understood and may not be emphasised by the authors of such work. However, the underpinning rationale for work on effectors is to provide new methods for controlling pathogens. Here we describe some of the translational outputs of effector research.

\section{NATURAL RESISTANCE}

The function and evolution of induced plant defences has been described by the zigzag model (Jones \& Dangl, 2006) and is summarised in Figure 1 in the context of plant-nematode interactions. Plants are under constant attack from a wide range of potential pathogens. The majority of these pathogens are successfully repelled following detection of essential, conserved pathogen molecules (Pathogen-Associated Molecular Patterns - PAMPs) which activate the first layer of host defences PAMP-triggered immunity (PTI) - following perception by pattern-recognition receptors (PRRs). PTI may also be induced upon detection of the breakdown products of the plant cell wall, which are termed damage-associated molecular patterns (DAMPs). Successful biotrophic pathogens deliver effectors that suppress PTI and thus induce effector-triggered susceptibility (ETS). In order to counter this, a second layer of immune receptors is present encoded by resistance $(R)$ genes. Resistance proteins detect the presence of effectors and activate effector-triggered immunity (ETI). ETI is frequently accompanied by a strong, localised cell death, termed the hypersensitive reaction (HR). Effectors that are recognised by resistance proteins are termed avirulence (Avr) factors.

The HR arising from the recognition of an Avr gene product by its cognate $\mathrm{R}$ protein can be readily visualised as a patch of cell death in some plants (Figure 2). This can be achieved either by transiently expressing the Avr gene alone in a plant carrying the appropriate $R$ gene (Figure $2 \mathrm{~A}$ ) or by transiently expressing both the Avr effector and the $R$ genes in a plant (Figure 2B \& 2E). Knowledge of an Avr effector therefore offers several potential practical benefits. Perhaps most importantly an Avr gene can be used as a tool to assist in the identification of the corresponding $R$ gene, by acting as a probe that reveals the presence of the $R$ gene in a given sample. The use of effectors in these resistance screening approaches has recently been reviewed (Du \& Vleeshouwers, 2014), and 
includes several examples of identification of $R$ genes against the late blight pathogen Phytophthora infestans. For example, knowledge of the R3a/Avr3a matching pair enabled the subsequent identification of the closely linked, but functionally distinct, $R 3 b$ resistance gene and its cognate Avr gene Avr3b (Li et al., 2011). Similarly, effectors can also be used as tools to identify novel resistance sources. Vleeshouwers et al. (2008) screened a range of wild Solanaceous species with 54 predicted $P$. infestans effectors and were able to identify orthologues of Rpi-blb-1 resistance gene from Solanum stoloniferum and S. papita. Similarly, Van Weymers et al. (2016) screened 126 wild diploid Solanum accessions with $P$. infestans isolates and subsequently identified functional Rpi-vnt1.1 homologs in S. okadae amongst other $R$ genes by screening 82 conserved effectors. Knowledge of an Avr gene can also be used for tracking the presence of an $R$ gene in a population of plants used in a breeding programme by transient expression in leaves. The utility of integrating effector screening in a breeding program and in $R$ gene cloning has been illustrated recently by the characterisation of an R2 homolog from the Swedish potato breeding clone SW93-1015 that confers efficient broad spectrum resistance to $P$. infestans under field conditions (Lenman et al., 2016). This approach offers the prospect of substantial savings of time and resource, compared to screening segregating populations with nematodes.

Knowledge of effectors/Avr genes can also be used to predict the durability of an $R$ gene in a field situation. An Avr gene that accumulates mutations in response to selection pressure from the host may no longer be recognised by its cognate R protein, although there may also be constraints on the level of changes that can be accommodated while retaining function. It therefore follows that an $A v r$ gene that is relatively invariant at a population level is likely to be recognised by an $R$ gene product that is durable. Conversely, extensive variation in an effector sequence is likely to be characteristic of an Avr gene that evades recognition by what is probably a less durable $R$ gene. This property can be readily observed in the one Avr gene (AvrGpa2 otherwise known as Gp-RBP-1) that has been identified from plant-parasitic nematodes to date (Sacco et al., 2009). The potato Gpa2 resistance has been overcome by populations of G. pallida present in Europe and this is reflected by the presence in G. pallida populations of multiple alleles of the Avr gene that contain a point mutation in the site which determines recognition. Indeed, strong selection pressure on this amino acid residue, and on several others, has been demonstrated (Carpentier et al., 2012). Similar analyses with $P$. infestans have shown that polymorphisms in a range of Avr genes partly explain the understanding of effector biology can therefore inform resistance deployment and breeding strategies. 
In the longer term, and given the appropriate public acceptance, knowledge of the recognition specificities of an R/Avr gene combination can be used to expand recognition in generating a modified version of the $R$ gene that recognises forms of the Avr gene that would normally evade detection. Two forms of the Avr3a gene are present in P. infestans populations; $A v r 3 a^{K l}$ is recognised by $R 3 a$ whereas $A v r 3 a^{E M}$, which has polymorphisms present at two positions in the Avr3a protein, evades recognition. Two studies have shown that introducing amino acid changes in R3a by point mutation or gene shuffling can generate forms of the protein that recognise both $\mathrm{Avr} 3 \mathrm{a}^{\mathrm{Kl}}$ and Avr3a $^{\mathrm{EM}}$ (Chapman et al., 2014; Segretin et al., 2014). Although there may be issues in converting this recognition into resistance in plants, this technology offers the clear potential to manipulate $R$ genes into a more durable form where knowledge of the corresponding effector is available.

Functional studies on effectors that have been identified from plant-parasitic nematodes frequently include an analysis of the importance of the effector by knocking down expression using RNA interference (RNAi). Nematode effectors can be targeted using RNAi by inducing uptake of double stranded RNA (dsRNA) by second stage juveniles (e.g Chen et al., 2005; Bakhetia et al., 2008) or by producing genetically modified plants that express a dsRNA hairpin from an appropriate construct (e.g Eves van den Akker et al., 2014a). The aim of such studies is generally to demonstrate the importance of an effector in the pathogenic process or, given sufficiently detailed phenotyping, to understand the function of the effector in the nematode life cycle. Such studies also allow effectors to be identified that might represent good targets for the development of future control methods by generating plants that express dsRNA targeting the effector sequence. In line with this idea, mining the genomes of root-knot nematodes through an evolutionary and comparative genomics approach identified 15,952 genes, including 993 effector-like proteins, that are conserved in genomes of plant-parasitic species but absent from non-target genomes of chordates, plants, annelids, insect pollinators and molluscs (Danchin et al., 2013). Sixteen of these were tested in infestation assays on tomato, using siRNA-treated $M$. incognita, and 12 showed significant and reproducible reduction of nematode parasitism. Host-mediated silencing is an appealing strategy for nematode control, partly due to the exquisite specificity of the RNAi process itself, in which only genes that are very similar in sequence to the silencing dsRNA will be targeted, but also because effectors in particular are often highly restricted to specific pathogen groups, as illustrated by the fact that very little overlap is present between the effector complement of G. pallida and that of 
root-knot nematodes (Cotton et al., 2014). This suggests that an RNAi strategy targeting effector(s) has the potential to be highly specific and thus may allow off-target effects to be minimised.

The most complete example of the use of this strategy to date concerns the $16 \mathrm{D} 10$ effector of the root-knot nematode $M$. incognita. This effector targets a SCARECROW transcription factor in plants (Huang et al., 2006a) and subsequent work showed that knocking out expression of the 16D10 effector by RNAi in vitro leads to a failure of parasitism (Huang et al., 2006b). In addition, Arabidopsis expressing dsRNA hairpins targeting 16D10 were resistant to $M$. incognita and to closely related Meloidogyne species (Huang et al., 2006b). Likewise, host-mediated RNAi silencing targeting the $M$. incognita 16D10 in transgenic grapevine hairy roots efficiently decreased nematode reproduction (Yang et al., 2013). A similar approach has shown that targeting the Meloidogyne chitwoodi homologue of 16D10 also gives resistance in Arabidopsis and in potato (Dinh et al., 2014). This demonstrated that RNAi of an effector can be used in a crop plant as well as in a model system. A similar strategy has been used to analyse the function of the M. incognita 8D05 effector gene, which is known to interact with a host protein likely to be involved in water and solute transport. Generation of transgenic Arabidopsis expressing a dsRNA targeting the 8D05 effector gene gave over $90 \%$ control in vitro, validating this effector as a potential control target (Xue et al., 2013).

Although the studies described above provide, at first sight, compelling evidence that RNAi targeting effectors (or indeed any other important nematode gene) represents a promising control strategy, the sustainability of such resistance has not yet been demonstrated and a note of caution is required. The first description of RNAi in nematodes was made almost 20 years ago (Fire et al., 1998) and the first publication demonstrating the applicability of this technique to plant-parasitic nematodes appeared more than 10 years ago (Urwin et al., 2002). Various proof-of-concept studies, such as those described above, have subsequently appeared but there are no cultivars available that use RNAi to control nematodes. It has recently been shown that constructs generating dsRNA targeting nematode genes can become silenced in transgenic plants due to methylation of the promoter region and that this effect may become more pronounced in successive generations (Kyndt et al., 2013). There may therefore be significant technical hurdles to be overcome before RNAi can be deployed as a tool against nematodes.

\section{LONGER TERM OUTPUTS (1): TARGETING THE HOST TARGETS OF EFFECTORS}

One of the ways that the function of a novel effector can be probed is to screen a yeast twohybrid library with the effector in order to identify host proteins that interact with, and may therefore be targeted by, the effector. This approach has been used widely and has shown that a 
221 variety of host proteins and pathways are targeted by nematode effectors. These include transcription factors (Huang et al., 2006a), auxin transporters (Lee et al., 2011), proteins involved in cell wall remodelling (Hewezi et al., 2008) and putative $R$ genes (Rehman et al., 2009). This knowledge offers a further opportunity for new control strategies as it may be feasible to identify, or to generate, variants of the host proteins (also referred as susceptibility genes) that are still functional but that are no longer amenable to manipulation by the effector (van Schie \& Takken, 2014). Structural information about how the interaction between the effector and its target can help in this regard and a similar approach has been used to demonstrate how changes in an effector sequence affect its ability to interact with a host target (King et al., 2014). Once a target has been identified and the region that is important for interaction with the effector determined, variants of the target can be sought, or induced, that do not interact with the effector. The development of TILLING (Targeting Induced Local Lesions In Genomes) based approaches offer the hope that progress can be made in this area (McCallum et al., 2000). TILLING is a method in which mutagenesis is coupled with extremely high-throughput screening techniques that identify the sites of the induced mutations. The use of TILLING as a tool for improvement of crops has recently been reviewed (Chen et al., 2014). In an alternative approach - EcoTILLING - natural variants of the host species are sought that show a desired trait and the same high-throughput techniques are subsequently used to identify variation that is associated with the trait. This tool has been used, for example, to identify variants in $R$ genes against powdery mildew and to seek new resistance sources against viruses (Ibiza et al., 2010; Mejlhede et al., 2006). Looking further ahead, new genome editing tools such as CRISPRs and TALENs (reviewed by Mahfouz et al., 2014) may offer an alternative route to modifying host sequences to the disadvantage of pathogens. These approaches may not just be limited to modifying the protein targets of pathogen effectors. Some effectors may exert their activity by binding to DNA in order to modify host gene expression; the bacterial TAL effectors providing the best studied examples of these (e.g. Kay et al., 2007). Modifying the region of the host genomic DNA that effectors need to bind to may therefore offer an alternative route to control (Wulff et al., 2011).

\section{LONGER TERM OUTPUTS (2): NON-HOST RESISTANCE}

Non-host resistance (NHR) is the term used to describe the phenomenon that most plants are resistant to most pathogens. The corollary of this is that most pathogens have a very limited host range, although there are clear exceptions to this rule including some root-knot nematode species. Understanding the mechanisms underlying NHR offers the prospect of identifying resistance that is, 
by definition, broad-spectrum and durable. The potential applications of NHR in crop improvement have recently been reviewed (Lee et al., 2016). NHR is often multi-tiered (Thordal-Christensen, 2003; Gill et al., 2015) but although structural and chemical barriers play a role in some cases of NHR, it is thought that effectors are central in the majority of cases. It has been argued (Schulze-Lefert \& Panstruga, 2011) that NHR in plants distantly related to the host of a pathogen occurs as a result of a failure to suppress PTI, and that the NHR response in such species occurs as a result of PTI responses mediated by the plasma membrane localized PAMP receptors. This may occur due to co-evolution between host and pathogen leading to highly adapted effectors that are unable to interact with their targets in non-host species. NHR may be engineered by transferring PRR, that are otherwise absent, into host plants to create defence responses that pathogens are unable to circumvent due to a lack of adapted effector(s). The ground-breaking demonstration that broad-spectrum defence against bacterial pathogens can be acquired by heterologous expression of a PRR was reported by Lacombe et al. in 2010, where the elongation factor Tu receptor (EFR) from Arabidopsis was transferred into two Solanaceous plants, tomato and Nicotiana benthamiana. Further demonstration of the efficiency of this approach has been provided in two recent studies (Schoonbek et al., 2015; Schwessinger et al., 2015), showing that transfer of EFR in wheat and rice can also enhance bacterial disease resistance in cereals. This also suggests that both dicot and monocot plants contain all necessary components for EFR signalling, further revealing that immune signalling pathways may be conserved across distant phyla and that transfer of PRR across plant families may also prove to be less problematic than inter-family $R$ gene transfer. In non-host species that are more closely related to the host species, NHR may occur as a result of ETI, implying the existence of highly durable $R$ genes that recognise the pathogen and whose action cannot be circumvented by the pathogen (Schulze-Lefert \& Panstruga, 2011). Knowledge of pathogen effectors offers the potential to identify the $R$ genes that underlie NHR in non-host species. As a first step in this process one effector (HopQ1-1) has been identified from the tomato bacterial speck agent Pseudomonas syringae pv. tomato as the sole avirulence determinant responsible for the failure of the model strain DC3000 to cause disease in $N$. benthamiana (Wei et al., 2007; Figure 2C). Conversely, heterologous expression of hopQ1-1 in the tobacco wildfire pathogen P. syringae pv. tabaci 11528 rendered this strain avirulent in its susceptible host $N$. benthamiana. However, the hopQ1-1 deletion did not extend the host range of DC3000 to tobacco Nicotiana tabacum, indicating that the mutation does not confer some general virulence benefit to DC3000. Effector-mediated recognition in non-host plants can also trigger cell death, as seen in R/Avr-mediated resistance (Figure 2D and 2E). As an example, Phytophthora capsici effector PcAvr3a1 provokes a cell death response upon transient expression in (non-host) N. tabacum and other related non-host species (Vega-Arreguin et al., 2014). Furthermore, 
host-mediated silencing of PcAvr3a1 in the pathogen allowed infection of resistant tobacco, confirming the importance of effector recognition in NHR.

\section{CONCLUDING REMARKS}

Effector biology is currently a highly topical issue, with developments in genomics and functional genomics enabling beautifully detailed studies of these proteins. As well as revealing the tools used by pathogens to manipulate their hosts, each effector acts as a probe for the plant immune system allowing us to develop a better understanding of both sides of the host-parasite interaction (Lee et al., 2013). The interactions of effectors with R proteins, and indispensable roles that they play in pathogen biology, mean that they also offer the prospect of significant practical gains. Effectors already form an integral part of the breeding process for resistance against the late blight pathogen P. infestans (Du \& Vleeshouwers, 2014). We consider it likely that this will soon be the case for other plant pathogens, including nematodes, as information on the effector complement of various economically important pathogens is established.

\section{Acknowledgements}

The James Hutton Institute receives funding from the Scottish Government. This work benefited from interactions funded through COST FA1208.

\section{References}

Andolfo, G., Jupe, F., Witek, K., Etherington, G.J., Ercolano, M.R. \& Jones, J.D.G. (2014). Defining the full tomato NB-LRR resistance gene repertoire using genomic and CDNA RenSeq. BMC Plant Biology 14, Article 120.

Bakhetia, M., Urwin, P.E. \& Atkinson, H.J (2008). Characterisation by RNAi of pioneer genes expressed in the dorsal pharyngeal gland cell of Heterodera glycines and the effects of combinatorial RNAi. International Journal for Parasitology 38, 1589-1597.

Bird, D. McK., Jones, J.T., Opperman, C., Kikuchi, T. \& Danchin, E.G.J. (2014). Signatures of adaptation to plant parasitism in nematode genomes. Parasitology 142, S71-S84.

Carpentier, J., Esquibet, M., Fouville, D., Manzanares-Dauleux, M.J., Kerlan, M.C \& Grenier, E. (2012). The evolution of the Gp-Rbp-1 gene in Globodera pallida induces multiple selective replacements. Molecular Plant Pathology 13, 546-555. 
Chapman, S., Stevens, L.J., Boevink, P.C., Engelhardt, S., Alexander, C.J., Harrower, B., Champouret, N., McGeachy, K., Van Weymers, P.S.M., Chen, X., Birch, P.R.J. \& Hein, I. (2014). Detection of the virulent form of AVR3a from Phytophthora infestans following artificial evolution of potato resistance gene $R 3 a$. PLoS One 9, e110158.

Chen, L., Hao, L.G., Parry, M.A.J., Phillips, A.L. \& Hu, Y.G. (2014). Progress in TILLING as a tool for functional genomics and improvement of crops. Journal of Integrative Plant Biology 56, 425443.

Chen, Q. Rehman, S., Smant' G. \& Jones J.T. (2005). Functional analysis of pathogenicity proteins of the potato cyst nematode Globodera rostochiensis using RNAi. Molecular Plant-Microbe Interactions 18, 621-625.

Cooke, D.E.L., Cano, L.M., Raffaele, S., Bain, R.A., Cooke, L.R., Etherington, G.J., Deahl, K.L., Farrer, R.A., Gilroy, E.M., Goss, E.M., Grunwald, N.J., Hein, I., MacLean, D., McNicol, J.W., Randall, E., Oliva, R.F., Pel, M.A., Shaaw, D.S., Squires, J.N., Taylor, M.C., Vleeshouwers, V.G.A.A., Birch, P.R.J., Lees, A.K. \& Kamoun, S. (2012). Genome analyses of an aggressive and invasive lineage of the Irish potato famine pathogen. PLoS Pathogens 8, e1002940.

Cotton, J.A., Lilley, C.J., Jones, L.M., Kikuchi, T., Reid, A.J., Thorpe, P., Tsai, I.J., Beasley, H., Blok, V.C, Cock, P.J.A., Eves-van den Akker, S., Holroyd, N., Hunt, M., Mantelin, S., Naghra, H. Pain, A., Palomares-Rius, JE., Zarowiecki, M., Berriman, M., Jones, J.T. \& Urwin, P.E. (2014). The genome and life-stage specific transcriptomes of Globodera pallida elucidate key aspects of plant parasitism by a cyst nematode. Genome Biology 15, R43.

Danchin, E.G.J., Arguel, M.-J., Campan-Fournier, A., Perfus-Barbeoch, L., Magliano, M., Rosso, M.N., Da Rocha, M., Da Silva, C., Nottet, N., Labadie, K., Guy, J., Artiguenave, F. \& Abad, P. (2013). Identification of novel target genes for safer and more specific control of root-knot nematodes from a pan-genome mining. PLoS Pathogens 9, e1003745.

Danchin, E.G.J., Guzeeva, E.A., Mantelin, S., Berepiki, A. \& Jones, J.T. (2016). Horizontal gene transfer from bacteria has enabled the plant-parasitic nematode Globodera pallida to feed on hostderived sucrose. Molecular Biology and Evolution 33, 1571-1579.

Dinh, P.T.Y., Brown, C.R. \& Elling, A.A. (2014). RNA interference of an effector gene Mc16D10L confers resistance against Meloidogyne chitwoodi in Arabidopsis and potato. Phytopathology 104, 1098-1106.

Djamei, A., Schipper, K., Rabe, F., Ghosh, A., Vincon, V., Kahnt, J., Osorio, S., Tohge, T., Fernie, I., Feussner, K., Meinicke, P., Stierhof, Y-D, Schwarz, H., Macek, B., Mann, M. \& Kahmann, R. (2011). Metabolic priming by a secreted fungal effector. Nature 478, 395-400. 
Du, J. \& Vleeshouwers, V.G.A.A. (2014). The Do's and Don'ts of effectoromics. In: Birch, P.R.J., Jones. J.T. \& Bos, J.I.B. (Eds), Plant-pathogen interactions: Methods and protocols. Methods in Molecular Biology 1127, 257-268.

Eves-van den Akker, S., Lilley, C.J., Jones, J.T. \& Urwin, P.E. (2014a). Identification and characterisation of a hyper variable apoplastic effector gene family of the potato cyst nematodes. PLoS Pathogens 10: e1004391.

Eves-van den Akker, S., Lilley, C.J., Danchin, E.G.J., Rancurel, C., Cock, P.J.A., Urwin, P.E. \& Jones, J.T. (2014b). The Nacobbus aberrans transcriptome reveals insights into the evolution of sedentary endoparasitism in plant-parasitic nematodes. Genome Biology \& Evolution 6, 2181-2194.

Eves-van den Akker, S., Laetsch, D.R., Thorpe, P., Lilley, C.J., Danchin, E.G.J., Da Rocha, M., Rancurel, C., Holroyd, N.E., Cotton, J.A., Szitenberg, A., Grenier, E., Montarry, J., Mimee, B., Duceppe, M.O., Boyes, I., Marvin, J.M.C., Jones, L.M., Yusup, H.B., Lafond-Lapalme, J., Esquibet, M., Sabeh, M., Rott, M., Overmars, H., Finkers-Tomczak, A., Smant, G., Koutsovoulos, G., Blok, V., Mantelin, S., Cock, P.J.A., Phillips, W., Henrissat, B., Urwin, P.E., Blaxter, M. \& Jones, J.T. (2016). The genome of the yellow potato cyst nematode, Globodera rostochiensis, reveals insights into the basis of parasitism and virulence. Genome Biology 17, Article 124.

Fire, A., Xu, S., Montgomery, M.K., Kostsas, S.A., Driver, S.E. \& Mello, C.C. (1998). Potent and specific genetic interference by double-stranded RNA in Caenorhabditis elegans. Nature 391, 806-811.

Gao, B.L., Allen, R., Maier, T., Davis, E.L., Baum, T.J. \& Hussey, R.S. (2003). The parasitome of the phytonematode Heterodera glycines. Molecular Plant-Microbe Interactions 16, 720-726.

Gill, U.S., Lee, S. \& Mysore, K.S. (2015). Host versus nonhost resistance: Distinct wars with similar arsenals. Phytopathology 105, 580-587.

Goverse, A. \& Smant, G. (2014). The activation and suppression of plant innate immunity by parasitic nematodes. Annual Review of Phytopathology 52, 243-265.

Haegeman, A., Jacob, J., Vanholme, B., Kyndt, T., Mitreva, M. \& Gheysen, G. (2009). Expressed sequence tags of the peanut pod nematode Ditylenchus africanus: The first transcriptome analysis of an Anguinid nematode. Molecular and Biochemical Parasitology 167, 32-40.

Haegeman, A., Joseph, S. \& Gheysen, G. (2011). Analysis of the transcriptome of the root lesion nematode Pratylenchus coffeae generated by 454 sequencing technology. Molecular and Biochemical Parasitology 178, 7-14.

Haegeman, A., Mantelin, S., Jones, J.T. \& Gheysen, G. (2012). Secretions of plant parasitic nematodes. Gene 492, 19-31.

Hewezi, T., Howe, P., Maier, T.R., Hussey, R.S., Mitchum, M.G., Dvis, E.L. \& Baum, T.J. (2008). Cellulose binding protein from the parasitic nematode Heterodera schachtii interacts with 
Arabidopsis pectin methylesterase: Cooperative cell wall modification during parasitism. The Plant Cell 20, 3080-3093.

Hofmann, J., Wieczorek, K., Blochl, A. \& Grundler, F.M.W. (2007). Sucrose supply to nematodeinduced syncytia depends on the apoplasmic and symplasmic pathways. Journal of Experimental Botany 58, 1591-1601.

Huang, G.Z., Gao, B.L., Maier, T., Allen, R., Davis, E.L., Baum, T.J. \& Hussey, R.S. (2003). A profile of putative parasitism genes expressed in the esophageal gland cells of the root-knot nematode Meloidogyne incognita. Molecular Plant-Microbe Interactions 16, 376-381.

Huang, G., Dong, R., Allen, R., Davis, E.L., Baum. T.J. \& Hussey, R.S. (2006a). A root-knot nematode secretory peptide serves as a ligand for a plant transcription factor. Molecular Plant-Microbe Interactions 19, 463-470.

Huang, G., Allen, R., Davis, E.L., Baum. T.J \& Hussey, R.S (2006b). Engineering broad root-knot resistance in transgenic plants by RNAi silencing of a conserved and essential root-knot nematode parasitism gene. Proceedings of the National Academy of Sciences of the USA 103, 14302-14306.

Hussey, R.S. \& Mimms, C.W. (1990). Ultrastructure of esophogeal glands and their secretory granuls in the root-knot nematode Meloidogyne incognita. Protoplasma 162, 99-107.

Ibiza, V.P., Canizares, J. \& Nuez, F. (2010). EcoTILLING in Capsicum species: searching for new virus resistances. BMC Genomics 11, 631.

Jones, J.D.G. \& Dangl, J.L. (2006). The plant immune system. Nature 444, 323-329.

Jones, J.T., Kumar, A., Pylypenko, L.A., Thirugnanasambandam, A., Castelli, L., Chapman, S., Cock, P.J., Grenier, E., Lilley, C.J., Phillips, M.S. \& Blok, V.C. (2009). Identification and functional characterisation of effectors in Expressed Sequence Tags from various life cycle stages of the potato cyst nematode Globodera pallida. Molecular Plant Pathology 10, 815-828.

Jaouannet, M., Magliano, M., Arguel, M.J., Gourges, M., Evangelisti, E., Abad, P. \& Rosso, M.N. (2013). The root-knot nematode calreticulin Mi-CRT is a key effector in plant defense suppression. Molecular Plant-Microbe Interactions 26, 97-105.

Jupe, F., Witek, K., Verweij, W., Śliwka, J., Pritchard, L., Etherington, G.J., Maclean, D., Cock, P.J., Leggett, R.M., Bryan, G.J., Cardle, L., Hein, I. \& Jones, J.D.G. (2013). Resistance gene enrichment sequencing (RenSeq) enables reannotation of the NB-LRR gene family from sequenced plant genomes and rapid mapping of resistance loci in segregating populations. The Plant Journal 76, 530-544.

Kay, S., Hahn, S., Marois, E., Hause, G. \& Bonas, U. (2007). A bacterial effector acts as a plant transcription factor and induces a cell size regulator. Science 318, 648-651. 
Kikuchi, T., Aikawa, T., Kosaka, H., Pritchard, L., Ogura, N. \& Jones, J.T. (2007). EST analysis of the pine wood nematode Bursaphelenchus xylophilus and B. mucronatus. Molecular and Biochemical Parasitology 155, 9-17.

King, S.R.F., McLellan, H., Boevink, P.C., Armstrong, M.R., Bukharova, T., Sukarta, O., Win, J., Kamoun, S., Birch, P.R.J. \& Banfield, M.J. (2014). Phytophthora infestans RXLR effector PexRD2 interacts with host MAPKKK epsilon to suppress plant immune signalling. The Plant Cell 26, 1345-1359.

Kumar, S., Schiffer, P.H. \& Blaxter, M. (2012). 959 Nematode Genomes: a semantic wiki for coordinating sequencing projects. Nucleic Acids Research 40, D1295-D1300.

Kyndt, T., Ji, H., Vanhome, B. \& Gheysen, G. (2013). Transcriptional silencing of RNAi constructs against nematode genes in Arabidopsis. Nematology 15, 519-528.

Lacombe, S., Rougon-Cardoso, A., Sherwood, E., Peeters, N., Dahlbeck, D., van Esse, H.P., Smoker, M., Rallapalli, G., Thomma, B.P.H.J., Staskawicz, B., Jones, J.D.G. \& Zipfel, C. (2010). Interfamily transfer of a plant pattern-recognition receptor confers broad-spectrum bacterial resistance. Nature Biotechnology 28, 365-369.

Lee, C., Chronis, D., Kenning, C., Peret, B., Hewezi, T., Davis, E.L., Baum, T.J., Hussey, R.S., Bennet, M. \& Mitchum, M.G. (2011). The novel cyst nematode effector protein $19 \mathrm{C07}$ interacts with the Arabidopsis auxin influx transporter LAX3 to control feeding site development. Plant Physiology $155,866-880$.

Lee, A.H.-Y., Middleton, M.A., Guttman, D.S. \& Desveaux, D. (2013). Phytopathogen type III effectors as probes of biological systems. Microbial Biotechnology 6, 230-240.

Lee, S., Hutton, S. \& Whitaker, V. (2016). Mini Review: potential applications of nonhost resistance for crop improvement. Frontiers in Plant Science 7, Article 997.

Lenman, M., Ali, A., Mühlenbock, P., Carlson-Nilsson, U., Liljeroth, E., Champouret, N., Vleeshouwers, V.G.A.A. \& Andreasson, E. (2016). Effector-driven marker development and cloning of resistance genes against Phytophthora infestans in potato breeding clone SW93-1015. Theoretical and Applied Genetics 129, 105-115.

Li, G., Huang, S., Guo, X., Li, Y., Yang, Y., Guo, Z., Kuang, H., Rietman, H., Bergervoet, M., Vleeshouwers, V.G.G.A., van der Vossen, E.A.G., Qu, D., Visser, R.G.F., Jacobsen, E. \& Vossen, J.H. (2011). Cloning and characterization of $R 3 b$; members of the $R 3$ superfamily of late blight resistance genes show sequence and functional divergence. Molecular Plant-Microbe Interactions 24, 1132-1142.

Lozano-Torres, J.L., Wilbers, R.H.P., Warmerdam, S., Finkers-Tomczak, A., Diaz-Granados, A., van Schaik, C.C., Helder, J., Bakker, J., Goverse, A., Schots, A. \& Smant, G. (2014). Apoplastic venom 

by cell surface receptors. PLoS Pathogens 10, e1004569.

Mahfouz, M.M., Piatek, A. \& Stewart, C.N. (2014). Genome engineering via TALENs and CRISPR/Cas9 systems: challenges and perspectives. Plant Biotechnology Journal 12, 1006-1014.

Maier, T.R., Hewezi, T., Peng, J.Q. \& Baum, T.J. (2013). Isolation of whole esophageal gland cells from plant-parasitic nematodes for transcriptome analyses and effector identification. Molecular Plant-Microbe Interactions 26, 31-35.

Manosalva, P., Manohar, M., von Reuss, S.H., Chen, S., Koch, A., Kaplan, F., Choe, A., Micikas, R.J., Wang, X., Kogel, K.-H., Sternberg, P.W., Williamson, V.M., Schroeder, F.C. \& Klessig, D.F. (2015). Conserved nematode signalling molecules elicit plant defenses and pathogen resistance. Nature Communications 6, Article 7795.

Mantelin, S., Thorpe, P. \& Jones, J.T. (2015). Suppression of plant defences by plant-parasitic nematodes. In: Advances in Botanical Research. (Escobar, C. and Fenoll, C., eds.). Elsevier Ltd; Oxford UK, 325-337.

McCallum, C.M., Comai, L., Greene, E.A. \& Henikoff, S. (2000). Targeting Induced Local Lesions In Genomes (TILLING) for plant functional genomics. Plant Physiology 123, 439-442.

Mei, Y., Thorpe, P., Guzha, A., Haegeman, A., Blok, V.C., MacKenzie, K., Gheysen, G., Jones, J.T \& Mantelin, S. (2015). Only a small subset of the SPRY domain gene family in Globodera pallida is likely to encode effectors, two of which suppress host defences induced by the potato resistance gene Gpa2. Nematology 17, 409-424.

Mejlhene, N., Kyjovska, Z., Backes, G., Burhenne, K., Rasmussen, S.K. \& Jahoor, A. (2006). EcoTILLING for the identification of allelic variation in the powdery mildew resistance genes Mlo and Mla of barley. Plant Breeding 1125, 461-467.

Mitchum, M.G., Hussey, R.S., Baum, T.J., Wang, X., Elling, A.A., Wubben, M. \& Davis, E.L. (2013). Nematode effector proteins: an emerging paradigm of parasitism. New Phytologist 199, 879894.

Niu, J., Liu, P., Liu, Q., Chen, C., Guo, Q., Yin, J., Yang, G. \& Jian, H. (2016). Msp40 effector of rootknot nematode manipulates plant immunity to facilitate parasitism. Scientific Reports 6, Article 19443.

Noon, J.B., Hewezi, T.A.F., Maier, T.R., Simmons, C., Wei, J.-Z., Wu, G., Llaca, V., Deschamps, S., Davis, E., Mitchum, M., Hussey, R.S. \& Baum, T.J. (2015). Eighteen new candidate effectors of the phytonematode Heterodera glycines produced specifically in the secretory esophageal gland cells during parasitism. Phytopathology 105, 1362-1372. 
Petitot, A.-S., Dereeper, A., Agbessi, M., Da Silva, C., Guy, J., Ardisson, M. \& Fernandez, D. (2016). Dual RNA-seq reveals Meloidogyne graminicola transcriptome and candidate effectors during the interaction with rice plants. Molecular Plant Pathology 17, 860-874.

Postma, W.J., Slootweg, E.J., Rehman, S., Finkers-Tomczak, A., Tytgat, T.O.G., van Gelderen, K., Lozano-Torres, J.L., Roosien, J., Pomp, R., van Schaik, C., Bakker, J., Goverse, A. \& Smant, G. (2012). The effector SPRYSEC-19 of Globodera rostochiensis suppresses CC-NB-LRR mediated disease resistance in plants. Plant Physiology 160, 944-954.

Rehman, S., Postma, W., Tytgat, T., Prins, P., Qin, L., Overmars, H., Vossen, J., Spiridin, L-N., Petrescu, A.J., Goverse, A., Bakker, J. \& Smant, G. (2009). A secreted SPRY domain-containing protein (SPRYSEC) from the plant-parasitic nematode Globodera rostochiensis interacts with a CC-NBLRR protein from a susceptible tomato. Molecular Plant-Microbe Interactions 22, 330-340.

Sacco, M.A., Koropacka, K., Grenier, E., Jaubert, M.J., Blanchard, A., Goverse, A., Smant, G. \& Moffett, P. (2009). The cyst nematode SPRYSEC protein RBP-1 elicits Gpa2- and RanGAP2dependent plant cell death. PLoS Pathogens 5, e1000564.

Schoonbeek, H.j., Wang, H.H., Stefanato, F.L., Craze, M., Bowden, S., Wallington, E., Zipfel, C. \& Ridout, C.J. (2015). Arabidopsis EF-Tu receptor enhances bacterial disease resistance in transgenic wheat. New Phytologist 206, 606-613.

Schulze-Lefert, P. \& Panstruga, R. (2011). A molecular evolutionary concept connecting nonhost resistance, pathogen host range and pathogen speciation. Trends in Plant Sciece 16, 117-125.

Schwessinger, B., Bahar, O., Thomas, N., Holton, N., Nekrasov, V., Ruan, D., Canlas, P.E., Daudi, A., Petzold, C.J., Singan, V.R., Kuo, R., Chovatia, M., Daum, C., Heazlewood, J.L., Zipfel, C. \& Ronald, P.C. (2015). Transgenic expression of the dicotyledonous pattern recognition receptor EFR in rice leads to ligand-dependent activation of defense responses. PLoS Pathogens 11, e1004809.

Segretin, M.E., Pais, M., Franschetti, M., Chaparro-Garcia, A., Bos, J.I.B., Banfield, M.J. \& Kamoun, S. (2014). Single amino acid mutations in the potato immune receptor R3a expand response to Phytophthora effectors. Molecular Plant-Microbe Interactions 27, 624-637.

Steuernagel, B., Periyannan, S.K., Hernandez-Pinzon, I., Witek, K., Rouse, M.N., Yu, G., Hatta, A., Ayliffe, M., Bariana, H., Jones, J.D.G., Lagudah, E.S. \& Wulff, B.B.H. (2016). Rapid cloning of disease-resistance genes in plants using mutagenesis and sequence capture. Nature Biotechnology 34, 652-655.

Streubel, J., Pesce, C., Hutin, M., Koebnik, R., Boch, J. \& Szurek, B. (2013). Five phylogenetically close rice SWEET genes confer TAL effector-mediated susceptibility to Xanthomonas oryzae pv. oryzae. New Phytologist 200, 808-819. 
Thordal-Christensen, H. (2003). Fresh insights into processes of nonhost resistance. Current Opinion in Plant Biology 6, 351-357.

Thorpe, P., Mantelin, S., Cock, P.J.A., Blok, V.C., Coke, M.C., Eves-van den Akker, S., Guzeeva, E., Lilley, C.J., Smant, G., Reid, A.J., Wright, K.M., Urwin, P.E \& Jones, J.T. (2014). Genomic characterisation of the effector complement of the potato cyst nematode Globodera pallida. BMC Genomics 15, Article 923.

Urwin, P.E., Lilley, C.J. \& Atkinson, H.J. (2002). Ingestion of double-stranded RNA by preparasitic juvenile cyst nematodes leads to RNA interference. Molecular Plant-Microbe Interactions 15, 747-752.

van Schie, C.C.N. \& Takken, F.L.W. (2014). Susceptibility genes 101: how to be a good host. Annual Review of Phytopathology 52, 24.21-24.31.

Van Weymers, P.S.M., Baker, K., Chen, X., Harrower, B., Cooke, D.E.L., Gilroy, E.M., Birch, P.R.J., Thilliez, G.J.A., Lees, A.K., Lynott, J.S., Armstrong, M.R., McKenzie, G., Bryan, G.J. \& Hein, I. (2016). Utilizing 'Omic' technologies to identify and prioritize novel sources of resistance to the oomycete pathogen Phytophthora infestans in potato germplasm collections. Frontiers in Plant Science 7, Article 672.

Vega-Arreguin, J.C., Jalloh, A., Bos, J.I.B. \& Moffett, P. (2014). Recognition of an Avr3a homologue plays a major role in mediating non-host resistance to Phytophthora capsici in Nicotiana species. Molecular Plant-Microbe Interactions 27, 770-780.

Vleeshouwers, V.G.A.A., Rietman, H., Krenek, P., Champouret, N., Young, C., Oh, S.K., Wang, M., Bouwmeester, K., Vosman, B., Visser ,R.G.F., Jacobsen, E., Govers, F., Kamoun, S. \& van der Vossen, E.A.G. (2008). Effector genomics accelerates discovery and functional profiling of potato disease resistance and Phytophthora infestans avirulence genes. PloS One 3, e2875.

Wei, C.-F., Kvitko, B.H., Shimizu, R., Crabill, E., Alfano, J.R., Lin, N.-C., Martin, G.B., Huang, H.-C. \& Collmer, A. (2007). A Pseudomonas syringae pv. tomato DC3000 mutant lacking the type III effector HopQ1-1 is able to cause disease in the model plant Nicotiana benthamiana. The Plant Journal 51, 32-46.

Wubben, M.J., Callahan, F.E. \& Scheffler, B.S. (2010). Transcript analysis of parasitic females of the sedentary semi-endoparasitic nematode Rotylenchulus reniformis. Molecular and Biochemical Parasitology 172, 31-40.

Wulff, B.B.H., Horvath, D.M. \& Ward, E.R. (2011). Improving immunity in crops: new tactics in an old game. Current Opinion in Plant Biology, 14, 468-476. 
Xue, B., Hamamouch, N., Li, C., Huang, G., Hussey, R.S., Baum, T.J. \& Davis, E.L. (2013). The 8D05 parasitism gene of Meloidogyne incognita is required for successful infection of host roots. Phytopathology 103, 175-181.

555

Yang, Y.A., Jittayasothorn, Y., Chronis, D., Wang, X.H., Cousins, P. \& Zhong, G.Y. (2013). Molecular characteristics and efficacy of 16D10 siRNAs in inhibiting root-knot nematode infection in transgenic grape hairy roots. PLoS One 8, e69463.

558 Zhang, L., Davies, L.J. \& Elling, A.A. (2015). A Meloidogyne incognita effector is imported into the 559 nucleus and exhibits transcriptional activation activity in planta. Molecular Plant Pathology 16, 560 48-60.

561 
563 Figure 1: The zigzag model in context of plant-nematode interactions. In 2006 Jones \& Dangl established the zigzag model to illustrate the quantitative output of the plant immune system in response to microbes but the concept has proven to be more broadly applicable to pests and pathogens. Components of the zigzag model that have been identified in plant-nematode interactions are shown in bold red type. The conceptual arms-race between host and pathogens can be depicted in four major phases. In phase I, conserved pathogen-associated molecular patterns (PAMPs; represented by the letter $\mathrm{P}$ in the pink forms) are recognised in plants by cell surface pattern-recognition receptors (PRRs) leading to induction of PAMP-triggered immunity (PTI). The only PAMP from plant-parasitic nematode identified to date is a pheromone, the ascaroside 18 (Ascr\#18; Manosalva et al., 2015), but its cognate PRR is not yet known. In phase II, adapted pathogens secrete effectors into the host that interfere with PTI, leading to effector triggered susceptibility (ETS). Several nematode effectors (represented by the letter E in the blue clouds) have been characterisd that can supress PTI responses (see review by Mantelin et al., 2015). In phase III, particular effectors (represented in the blue clouds by the letter A for "Avirulence factors") are detected by a second layer of plant resistance receptors (products of the $R$ genes), activating effector-triggered immunity (ETI) which in most cases leads to the induction of a hypersensitive plant cell-death reaction (HR). Very few nematode $R$ genes have been cloned (see review by Goverse \& Smant, 2014) and only one avirulence effector has been identified so far, the Globodera pallida RBP-1 SPRYSEC effector AvrGpa2 (Sacco et al., 2009). In phase IV, as pathogen and host coevolve new effectors and $R$ genes, susceptibility or resistance predominate in turn. Avirulence factors (A) maybe lost or modified to avoid recognition by cognate $\mathrm{R}$ proteins (as is the case for RBP-1) and perhaps new effectors are gained $(B, C, D)$ that are able to suppress ETI. Such activity has been demonstrated for the ubiquitin carboxyl extension protein GrUBCEP12 and many SPRYSEC effectors (see review by Mantelin et al., 2015).

Figure 2: Effector-mediated cell death in plants. (A \& B) A typical hypersensitive reaction is elicited by recognition of Globodera pallida effector Gp-RBP-1 (StGpa2-cognate avirulence factor) in Agrobacterium tumefaciens-based transient expression assay in potato accession Cara containing the StGpa2 resistance gene (A) or by transient co-expression of both StGpa2 and Gp-RBP-1 in Nicotiana benthamiana leaf (B). Conversely, eGFP control in potato and either StGpa2 or Gp-RBP-1 expressed alone in $N$. benthamiana do not induce a response in plants. Transient expressions were performed with untagged constructs for StGpa2, Gp-RBP-1 (Sacco et al., 2009) and eGFP control as described in Mei et al. 2015, by infiltration of $A$. tumefaciens strains at an $\mathrm{OD}_{600 \mathrm{~nm}}$ of 0.5 . Symptoms 
596 observed under white light 7 days post infiltration. Infiltrated areas are indicated by dashed circles.

597 (C-D-E) Effectors also participate in non-host resistance. (C) Wild-type Pseudomonas syringae 598 pathovar tomato (Pst) strain DC3000 can barely infect Nicotiana benthamiana while Pst mutant 599 strain CUCPB5460 lacking the type-III effector HopQ1-1 is able to cause disease in the non-host plant 600 (demonstrated by Wei et al., 2007). Necrotic disease symptoms observed 7 days after bacteria 601 infiltration at $\mathrm{OD}_{600 \mathrm{~nm}}$ of $1.10^{-4}$ in $10 \mathrm{mM} \mathrm{MgSO}_{4}$ solution. Infiltrated areas are circled. (D \& E) Cell 602 death is triggered specifically in non-host Nicotiana sy/vestris (D) by a Phytophthora infestans RXLR 603 effector (Pi-A) while transient expression of the same effector in the host plant $N$. benthamiana (E) 604 does not induce symptoms in the leaf. Another effector $(P i-B)$ as well as the $T d$-Tomato construct 605 used as control do not induce symptoms. Conversely, a typical hypersensitive reaction is elicited by 606 recognition of $P$. infestans effector Pi-Avr3a in the presence of the potato resistance protein StR3a in $607 N$. benthamiana leaf (E). Effectors and controls in binary vector pGRAB were transformed in $A$. 608 tumefaciens GV3101 and agro-infiltrated at an $\mathrm{OD}_{600 \mathrm{~nm}}$ of 0.1 in Nicotiana leaves (Mantelin and Hein, 609 personal communication). Symptoms observed under white light 7 days post inoculation. Infiltrated 610 areas are indicated by dashed circles. 


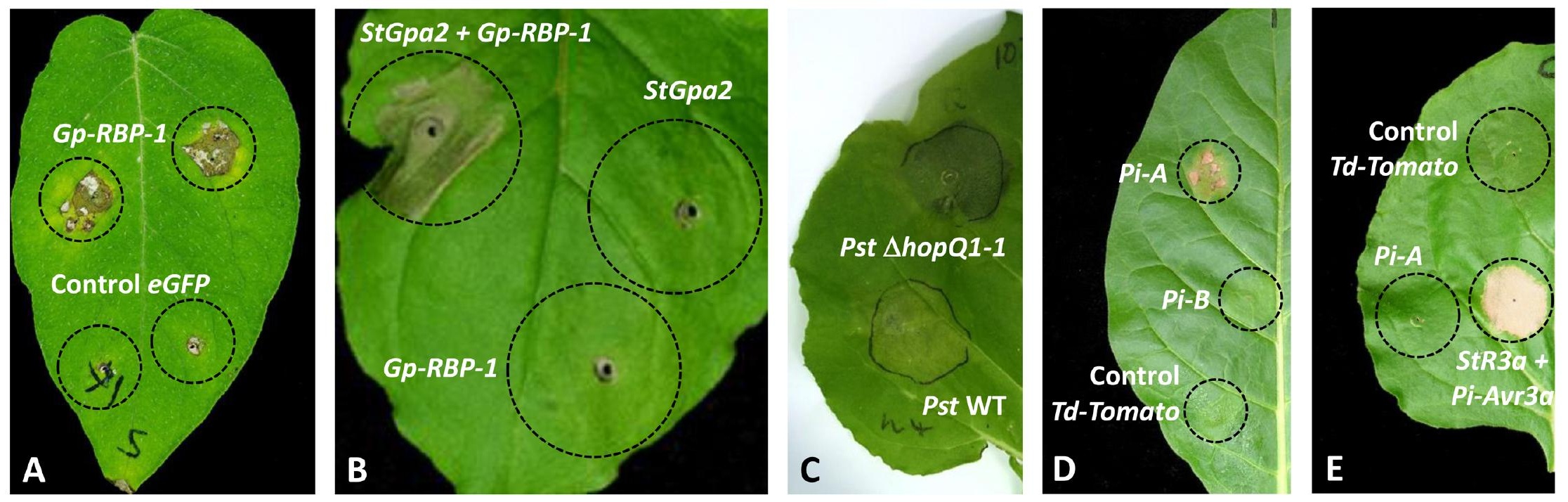

